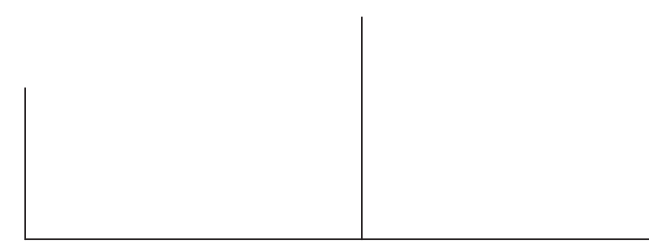

Rev. Latinoam. Psicop. Fund., II, 4, 52-61

\title{
Considerações sobre o diagnóstico em psicanálise*
}

\author{
Theodor S. Lowenkron
}

\begin{abstract}
O psicanalista deve se preocupar em fazer diagnóstico para realizar um tratamento psicanalítico? Seria desaconselhável o interesse do analista pelo diagnóstico, pois estaria "rotulando" seu paciente e prejudicando o futuro do processo analítico? Eis duas posições que podem ser aparentemente opostas, mas que se fazem presentes no cotidiano da prática na clínica psicanalítica. Será que essas posições podem influenciar a psicanálise do novo século?

Para introduzir o debate sobre o tema, apresento, de modo breve, o ponto de vista de Freud sobre a questão do diagnóstico em psicanálise, lanço mão de um caso clínico para exemplificar o exercício do diagnóstico psicanalítico, articulado com a contribuição de alguns autores para a compreensão do caso clínico em particular.

Há unanimidade entre os analistas de que a palavra é ferramenta essencial na tarefa terapêutica. Ela também deve ser considerada básica para a nomeação do sofrimento humano, para melhor encontrarmos, juntos com o paciente, a saída possível das trevas de seu mal-estar.
\end{abstract}

Palavras-chave: Processo psicanalítico, diagnóstico, caso clínico

* Classificado para apresentação no XVII Congresso Brasileiro de Psicanálise, Rio de Janeiro, Abril/1999. 


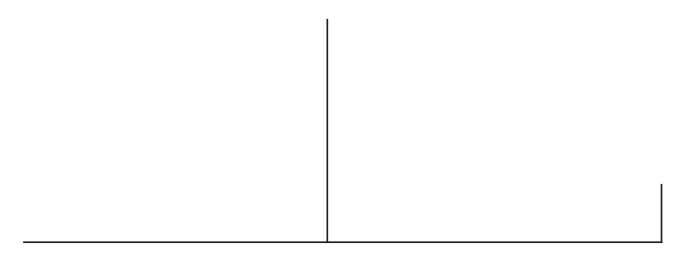

\section{Introdução}

O psicanalista deve se preocupar em fazer um diagnóstico preliminar para realizar um tratamento psicanalítico?

A formulação de um diagnóstico preliminar pelo psicanalista significaria interesse em "rotular" seu paciente, pondo em risco o futuro do processo analítico?

Eis duas posições que podem ser aparentemente opostas, mas que se fazem presentes no cotidiano da prática na clínica psicanalítica.

Será que essas posições podem influenciar a psicanálise do novo século?

Para introduzir o debate sobre o tema, apresento, de modo breve, o ponto de vista de Freud sobre a questão do diagnóstico em psicanálise, lanço mão de um caso clínico para exemplificar o exercício do diagnóstico psicanalítico, articulado com a contribuição de alguns autores para a compreensão do caso clínico em particular. Pretendo, desse modo, começar a responder às indagações apresentadas inicialmente, com vistas a contribuir para o debate maior sobre $O$ Homem, a Psicanálise e o Novo Século.

\section{Freud e o diagnóstico}

A importância da avaliação diagnóstica na clínica psicanalítica já está presente nos primórdios de sua prática. Freud (1895) chama a atenção, no entanto, para uma questão que se coloca paradoxalmente em relação a essa avaliação: a de que, embora a pertinência do diagnóstico só possa ser confirmada 


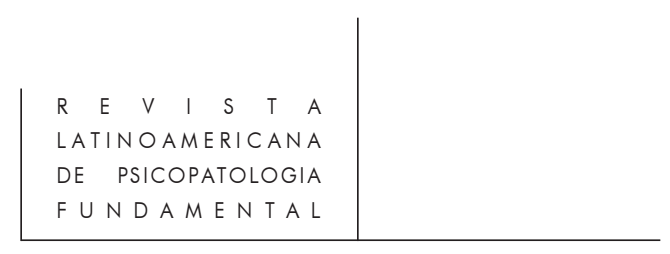

após uma análise profunda, o estabelecimento de um diagnóstico é condição sine qua non para a determinação do tratamento.

O psicanalista em seu procedimento de investigação no campo da prática clínica privilegia a escuta. Sua avaliação é predominantemente subjetiva, pois baseia-se principalmente no discurso do paciente e na subjetividade do analista que ouve. Assim, a investigação diagnóstica privilegia o espaço inter-subjetivo que se estabelece na comunicação de inconsciente para inconsciente. Segundo a metáfora da comunicação telefônica usada por Freud (1912), a escuta do analista capta e transforma, semelhante às vibrações telefônicas, segundo seu inconsciente, as ondas sonoras do dito do analisando com os derivativos de seu inconsciente.

\section{Caso Clínico}

Ao relatar o caso clínico de que me valho para a discussão do tema, as idéias expressas por Tuckett $(1994,1995)$ sobre comunicação dos fatos clínicos em psicanálise são bastante oportunas: tornar a experiência do analista o mais transparente possível é o único modo de tentar concretizar o que pode ser concretizado na situação irredutivelmente subjetiva que é o setting psicanalítico.

A análise de Rui foi um processo com duração de seis anos, mantido numa freqüência de quatro sessões semanais. Rui, quando veio à análise, era um jovem de 20 anos, filho único de um casal mais velho. O pai, já falecido, parecia a Rui, quando este era criança, ter idade de ser seu avô. Vinha à análise com manifestação sintomática de impotência, presente desde os 13 anos, e, na análise, se evidenciou uma estrutura de personalidade obsessiva.

No início da etapa final, foi introduzida a estória de impotência sexual do pai, com provável componente orgânico. Tanto o pai quanto a mãe procuravam encobrir essa situação de sofrimento do casal, por meio do enaltecimento das qualidades de conquistador do pai à época de sua juventude, favorecendo, de acordo com Winnicott (1982[1960]), a organização do falso self de Rui, auto-denominado garanhão. Desse modo, pode-se entender que o sintoma com o qual Rui veio à análise tinha o papel positivo de expressar seu conflito, em nível inconsciente, contra a submissão ao modelo familiar proposto.

A esses dados, acrescenta-se que a mãe havia the dito que a impotência do pai se iniciara à época em que Rui contava três anos de idade, dentro do período em que, segundo Freud (1916-17), o complexo de Édipo encontra-se no apogeu. Essa condição provavelmente favoreceu a escolha de objeto incestuoso pela mãe, o que dificultou enormemente a resolução do conflito nuclear de Rui na época da adolescência. A lacuna na satisfação materna, decorrente da impotência paterna, favoreceu junto à criança, que se fez testemunha disso, a abertura para uma suplência possível. 


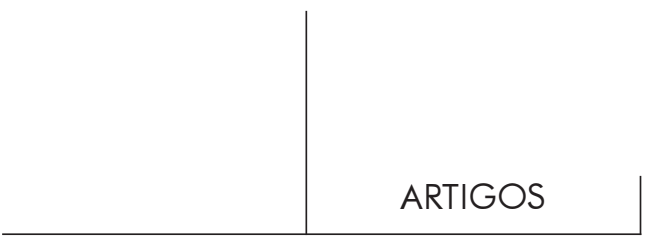

A mãe de Rui só verbalizou a estória de impotência do pai quando o marido veio a falecer. Rui contava 17 anos e reagiu com o que denominou surto de clarividência: mecanismo de negação do luto, expresso pela intensificação do falsoself e vivido no mito do garanhão. O conhecimento da impotência paterna mantevese recalcado até fase adiantada da análise. Somente quando questionado por uma jovem para quem se exibia como garanhão, deu-se conta da defesa maníaca contra sua condição de impotência, e, então, entrando em contato com o seu sofrimento, resolveu pedir ajuda.

O trabalho em conjunto com Rui no processo analítico, e a elaboração da neurose de transferência possibilitaram tanto a superação da sintomatologia quanto as transformações no modo de circulação do desejo em sua estrutura de personalidade.

\section{O diagnóstico do caso clínico}

Os tempos do diagnóstico

É evidente que à época do período do início da análise já havia um esboço diagnóstico, que me permitiu aceitar desenvolver o processo psicanalítico com Rui. Entretanto, no período final, estava em condições mais favoráveis para organizar o diagnóstico com mais elementos.

Neurose clínica ou caráter neurótico?

Dentro de uma perspectiva nosográfica freudiana que considera a existência das neuroses, das psicoses, das perversões e das afecções psicossomáticas, Rui está situado no terreno das neuroses.

A manifestação sintomática de impotência com a qual Rui vem para a análise está presente em todas as classes de neurose, conforme assinala Otto Fenichel (1973), não apontando ainda para uma especificidade de tipo de neurose.

No entanto, logo na primeira entrevista, quando Rui afirma querer tratar apenas da impotência e não precisar de ajuda para o todo de sua personalidade, evidenciase o uso do mecanismo de isolamento, ou seja, a tentativa de isolar seu sintoma de tal modo que suas conexões com o todo do sujeito ficam rompidas. Além disso, considerando o modo garanhão com que Rui se apresentava socialmente às moças, nos primeiros tempos da análise, demonstra o empenho no uso da formação reativa, tentativa inconsciente de minimizar a perda de auto-estima decorrente da condição de impotência que estava vivendo. Posto que os mecanismos de defesa principais da Neurose Obsessiva são o isolamento, a formação reativa e a anulação, Rui, então, lança mão de mecanismos que são típicos do espectro dessa forma de neurose 


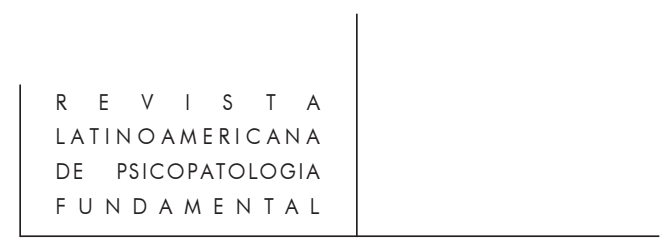

Então, dentre as Neuroses Clínicas, que se organizam em suas formas básicas nas apresentações Obsessiva, Histérica e Fóbica, Rui está no âmbito da Neurose Obsessiva. Entretanto, a formação reativa predomina como manifestação do caráter anal enquanto a anulação, mecanismo não prevalente no caso de Rui, é um dos mecanismos subjacentes nos sintomas da Neurose Obsessiva propriamente dita.

Numa tentativa de síntese e precisão podemos dizer que Freud (1895, 1896, 1908, 1909, 1917), definiu a especificidade da Neurose Obsessiva, considerando os mecanismos de defesa, a vida pulsional e o ponto de vista tópico. Os mecanismos de defesa presentes são o deslocamento do afeto para representações distantes do conflito original, o isolamento, a anulação retroativa. A vida pulsional é marcada pela regressão, com fixação na fase anal, expressando ambivalência entre amor e ódio. O ponto de vista tópico evidencia uma relação de sofrimento sob a forma da tensão entre o ego e um superego severo. Acrescenta-se o mecanismo de formação reativa, base do caráter anal, em que os sintomas não estão presentes.

Neste ponto, devemos deixar marcado que a fisionomia clínica das neuroses pode ser vista em dois níveis: sintomas neuróticos e caráter neurótico. No caráter neurótico o conflito defensivo não se traduz pela formação de sintomas, mas por traços de caráter, modos de comportamento, uma organização do conjunto da personalidade. A expressão caráter neurótico ou Neurose de Caráter evoca um quadro neurótico que não revela sintomas, mas acarretam dificuldades constantes na relação com o meio. Assim, considero que Rui está situado no âmbito do caráter neurótico obsessivo. O modo cavalheiresco demais, decorrente da educação esmerada que seus pais procuraram imprimir em sua infância, levou-o a certa inadaptação com o grupo de sua idade no início da adolescência, expressão da organização do caráter.

Já na Neurose Obsessiva o sujeito é atormentado por sintomas. São as obsessões ou pensamentos desagradáveis recorrentes que estão presentes, podendo chegar a realizar compulsões ou rituais, manifestações egodistônicas, ou seja, o sujeito experimenta como problemas e deseja livrar-se deles. Não é o que estava evidente na manifestação clínica apresentada por Rui. Se considerarmos que o Caráter Obsessivo se manifesta num comportamento perfeccionista e inflexível, vivido de modo geral sintônico, ou seja, visando evitar angústia, era o que predominava em Rui. Os traços de personalidade em Rui eram ego-sintônicos, uma vez que a manifestação sintomatológica de impotência sexual foi a que justificou demanda de análise e que ele afirmava, a princípio, que para o todo de sua personalidade não precisava de ajuda.

As primeiras contribuições sobre o Caráter Obsessivo ou anal são de Freud (1908), em "O caráter e o erotismo anal", e de Abraham (1921), em "Contribuições à teoria do caráter anal". Eles estabeleceram uma ligação entre traços de caráter, particularmente a obstinação, a parcimônia e a ordem, e a fase anal do 


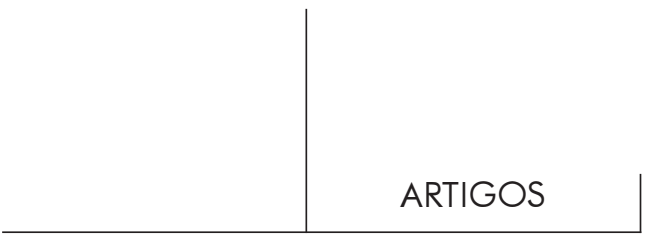

desenvolvimento. Os sujeitos com essas características de personalidade eram vistos como tendo regredido da ansiedade de castração da fase edípica para o período anal. A dificuldade que os sujeitos com caráter anal têm de expressar agressão foi relacionada com as lutas empreendidas com a figura materna no treinamento de hábitos de higiene; esses sujeitos têm uma história infantil marcada por dura disciplina. A teimosia poderia ser vista como consequiência da reação ao treinamento de higiene e à dura disciplina.

Gabbard (1985) apresenta elementos para além das vicissitudes da fase anal enfocando a auto-estima. Os sujeitos com caráter anal sofrem de insegurança por experimentarem a vivência de não terem sido suficientemente amados por seus pais. São também vistos como controladores pelas pessoas significativas de seu relacionamento, uma vez que, em decorrência da baixa auto-estima, não se sentem seguros no amor do outro, sendo levados a temer a perda das fontes de provisão de estima. Também a pulsão agressiva e destrutiva dirigida ao objeto, inconscientemente, pode contribuir para o temor de perder os outros. A busca de perfeição traz a fantasia de que se alcançarem esse estágio receberiam a aprovação parental que lhe faltou na infância. Os padrões rígidos e dogmáticos são compensadores da insegurança e ambivalência.

Apesar da distinção ser clara e útil entre Neurose Obsessiva e Caráter Obsessivo, existem similaridades nas bases psicanalíticas delas. Preferimos nos valer do conceito de Estrutura para superar a oposição entre neurose com ou sem sintomas, acentuando o modo de organização do desejo e da defesa, em vez de expressões manifestas do conflito, por meio de sintomas ou traços de caráter.

\section{Estrutura obsessiva}

Com base numa perspectiva epistemológica, uma estrutura é um modelo abstrato constituído de um conjunto de elementos e de leis de composição internas aplicadas a esses elementos.

Os traços diagnósticos estruturais surgem do dizer do analisando como expressão do desejo que se esboça em sua fala, são sinais que aparecem como índice do funcionamento da estrutura psíquica. A especificidade da estrutura do sujeito é predeterminada pela economia do desejo, testemunhada pela trajetória corrente de circulação do mesmo no espaço inter-subjetivo em questão.

Segundo Joël Dor (1991, 1991[1987]), devemos abordar a estrutura obsessiva a partir do processo do desejo do sujeito diante da função fálica. As vicissitudes do complexo de Édipo desenvolvem-se na dialética do ser e do ter, na elaboração que conduz o sujeito de uma posição, em que está identificado como falo da mãe, a uma segunda posição. Aceitando a castração simbólica, identifica-se ou 
com aquele que supostamente tem o falo ou, ao contrário, com aquele que supostamente não o tem.

$\mathrm{Na}$ dialética edipiana existe a possibilidade da passagem do ser ao ter. O pai faz a lei. Se o pai é suposto fazer lei à mãe, é sob a condição de que a mãe é suposta desejar o que não tem, o que o pai possui. É nesse deslocamento de atributo fálico que se efetua a passagem do ser ao ter. Foi significada para a criança no discurso materno que o objeto do seu desejo é estritamente dependente da pessoa do pai. Desse modo, pode mobilizar a criança na dimensão do ter.

De um lado, a criança percebe que a mãe é dependente do pai do ponto de vista do seu desejo, mas, por outro, não parece receber por inteiro do pai o que é suposto esperar. Essa lacuna na satisfação materna induz, junto à criança que se faz testemunha disso, a abertura favorável para uma suplência possível. Para a mãe existe uma vacância parcial dessa satisfação, sendo a criança um complemento possível.

$\mathrm{O}$ obsessivo tenta desconhecer ter feito a experiência da castração, a qual impede a ilusão de totalização, de domínio da globalização. Adere ao fantasma do gozo sem falta. A partir do momento em que atinge um objetivo, embarca numa nova empreitada.

A ambivalência entre a nostalgia fálica e a perda implicada pela castração inscreve o obsessivo numa posição estruturalmente específica com relação ao pai.

O isolamento tem a missão de desconectar um pensamento da sequiência lógica em que se inscreve. O elemento psíquico é neutralizado afetivamente. Os obsessivos falam de si a partir de um posto de observação neutro, lançando mão da narrativa e da racionalização.

A anulação retroativa é um processo compulsivo que consiste em colocar em cena, ou em ato, um comportamento oposto àquele que o sujeito acaba de afirmar. Esse mecanismo põe em evidência o conflito presente, a oposição entre o amor e o ódio para com o objeto de investimento. No mais das vezes, é a vertente do ódio que se esforça por anular o componente de amor. A dialética da estrutura obsessiva: escapar do seu desejo e anulá-lo o quanto puder a cada vez que se encontra engajado autenticamente.

A estratégia obsessiva consiste em se apropriar de um objeto vivo para transformá-lo em objeto morto, cuidando para que assim permaneça. O objeto pode deixar de representar o papel de morto, provocando inquietação e ódio do obsessivo que vive a mudança como uma traição.

\section{Conclusões}

Quanto ao referencial teórico utilizado na análise de Rui, baseei-me fundamentalmente em Freud. No entanto, seguindo o modelo da atenção flutuante do analista na sessão, optei pela abordagem do que denomino teoria flutuante, ou 


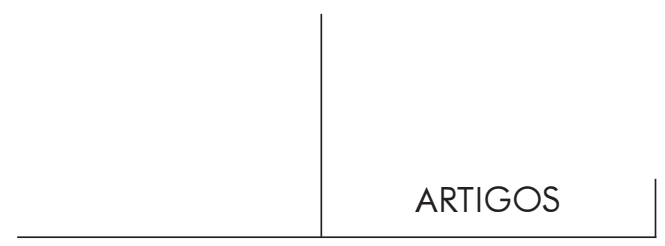

seja, busquei enriquecer com autores que melhor me ajudassem a lidar com a possibilidade de entender a situação clínica que procurava elaborar.

Rui proporcionou a oportunidade de follow-up, por meio de um telefonema interestadual, cerca de dois anos após o término da análise. Comunicou que havia se mudado de estado, casado e exercia sua atividade profissional em emprego público, alcançado por concurso que tinha feito à época do final da análise.

Retomando os questionamentos introdutórios, devemos afirmar que existe uma ambigüidade em torno da qual se coloca o problema do diagnóstico no campo da clínica: estabelecer um diagnóstico preliminar para decidir quanto à condução da cura, enquanto a pertinência deste diagnóstico só poderá ser confirmado após um certo tempo de tratamento. Na clínica analítica, o ato diagnóstico é necessariamente, de partida, um ato deliberadamente posto em suspenso e relegado a um devir. Mas é preciso, no entanto, circunscrever, o mais rápido possível, uma posição diagnóstica para decidir acerca da orientação da cura.

Quanto à especificidade da estrutura de um sujeito, essa se caracteriza por um perfil predeterminado da economia do seu desejo, que é governado por uma trajetória estereotipada, por assim dizer, de traços estruturais. E é em função dos amores edipianos que se constitui a entrada em cena de uma estrutura psíquica. Freud, a esse respeito, se referia à "escolha" da própria neurose. Esses amores edipianos são o desenvolvimento da relação que o sujeito trava com a função fálica, com a função paterna.

Para melhor precisar o diagnóstico é oportuno evidenciar claramente não apenas a noção de estrutura, mas também a distinção entre sintomas e traços estruturais. Uma discriminação rigorosa entre a identidade do sintoma e a identidade dos traços estruturais.

Por fim, há unanimidade entre os analistas de que a palavra é ferramenta essencial na tarefa terapêutica, the talking cure. Penso que ela também deve ser considerada básica para nomeação do sofrimento humano - o diagnóstico -, para melhor encontrarmos, juntos com o paciente, a saída possível das trevas de seu mal-estar.

\section{Referências bibliográficas}

ABraham, K. "Contribuições à teoria do caráter anal” (1921). In Teoria psicanalítica da libido - Sobre o caráter e o desenvolvimento da libido. Rio de Janeiro: Imago, 1970, pp.174-195.

Dor, Joël. Estruturas e clínica psicanalítica. Trad. Jorge Bastos e André Telles. Rio de Janeiro: Taurus-Timbre, 1991.

. Estrutura e perversões. Trad. Patrícia C. Ramos. Porto Alegre: Artes Médicas, 1991. 199 p. Obra original: Structure et perversions. Paris: Denoël, 1987. 
Fenichel, Otto. Teoria psicoanalitica de las neurosis. Trad. Mario Carlisky. Buenos Aires: Paidós, 5a ed., 1973.

Freud, S. "A psicoterapia da histeria" (1895), nos "Estudos sobre a histeria". In ESB, vol. II. Rio de Janeiro: Imago, pp. 311-363.

" Obsessões e fobias: seu mecanismo psíquico e sua etiologia" (1895). In ESB, vol. III. Rio de Janeiro: Imago, pp. 85-97.

"Novos comentários sobre as neuropsicoses de defesa" (1896). In ESB, vol. III. Rio de Janeiro: Imago, pp. 183-211.

"O caráter e o erotismo anal" (1908). In ESB, vol. IX. Rio de Janeiro: Imago, pp. 173-181.

"Notas sobre um caso de Neurose Obsessiva" (1909). In ESB, vol. X. Rio de Janeiro: Imago, pp. 13-250.

"Recomendações aos médicos que exercem a psicanálise" (1912). In ESB, vol.

XII. Rio de Janeiro: Imago, 1969, pp. 147-59.

"O desenvolvimento da libido e as organizações sexuais" (1916-1917),

"Conferências Introdutórias sobre Psicanálise", Parte III, Teoria Geral das Neuroses. In $E S B$, vol. XVI. Rio de Janeiro: Imago, 1969, pp. 375-395.

"As transformações do instinto exemplificadas no erotismo anal" (1917). In ESB, vol. XVII. Rio de Janeiro: Imago, 1976, pp. 157-166.

GABBARD, G. "The role of compulsiveness in the normal physician". J.A.M.A., 254: 29262929, p. 1985.

Tucket, D. "The conceptualisation and communication of clinical facts in psychoanalysis”. International Journal of Psycho-Analysis, v. 75, 1994.

"A conceituação e a comunicação dos fatos clínicos em psicanálise". Revista da Sociedade Psicanalítica de Porto Alegre, 1995, pp. 385-411.

Winnicott, D.W. "Distorção do ego em termos de falso e verdadeiro self" (1960). In 0 ambiente e os processos de maturação: estudos sobre a teoria do desenvolvimento emocional. Trad. Irineo Constantino Schuch Ortiz. Porto Alegre: Artes Médicas, 1982, pp. 128-139.

\section{Resumos}

¿El psicoanalista debe preocuparse en hacer diagnostico para realizar un tratamiento psicoanalitico? ¿No sería aconsejable el interés del analista por el diagnostico, pues estaría "rotulando" su paciente y perjudicando el futuro del proceso analítico? He dos posiciones que pueden ser aparentemente opuestas, pero que hallanse en el cotidiano de la practica en la clinica psicoanalitica. ¿Esas posiciones pueden influenciar la psicoanálisis del nuevo siglo?

Para iniciar la discusión sobre el tema, presento el punto de vista de Freud sobre la cuestión del diagnostico en psicoanálisis, presento un caso clínico para ejemplificar el ejercicio del diagnostico psicoanalítico, articulado con la contribución de algunos autores para la comprención del caso clínico en particular. 


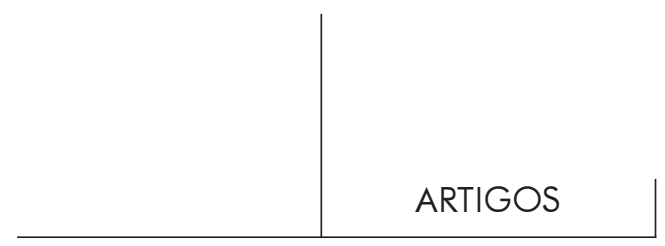

Los analistas son unánimes en decir que la palabra es la herramienta esencial en la tarea terapéutica. Ella también debe ser considerada basica para el nombramiento del sufrimiento humano, para mejor encontrarmos junto con el paciente la salida possible de las tinieblas de su malestar.

Palabras llave: Proceso analítico, diagnostico, clinica social

Est-ce que le psychanaliste doit se préoccuper en faire diagnostic pour réaliser un traitement psychanalitique? Serait inapproprié l'intérêt de l'analyste pour le diagnostic, car il serait en "étiquetant" son patient et préjudiciant le devenir du processus analytique? Voici deux positions qui peuvent être apparemment opposées, mais qui sont présents dans le quotidien de la pratique clinique psychanalitique. Ces propositions peuvent influencer la psychanalyse du nouveau siècle?

Pour introduire le debat sur ce sujet, je present le point de vue de Freud sur la question du diagnostic en psychanalyse, je présent un cas clinique pour exemplifiquer l'exercice du diagnostic psychanalitique, avec la contribution de quelques-uns auteurs pour la compréhension du cas clinique en particulier.

Il y a unanimité entre les analystes de que le mot est outil essentiel dans la tâche thérapeutique. Elle aussi doit être considerée essentiel pour la nomination du souffrance humain, pour trouver avec le patient l'issue possible de las ténèbres de son malaise.

Mots cles: Processus analytique, diagnostic, clinique social

Must the psychoanalyst worry about diagnosing so as to carry out a psychoanalytic treatment? Would the analyst's interest in the diagnosis be inadvisable, for he would be "labelling" his patient and harming the future of the analytic process? These two positions may seem apparently opposite, but they're both present in the daily practice in the psychoanalytic clinic. Can these positions influence the psychoanalysis of the new century?

In order to introduce the debate about the theme, I present briefly, Freud's point of view about the question of diagnosis in psychoanalysis and use a clinical case to examplify the usage of psychoanalytic diagnosis linked with some authors' contribution to the comprehension of the clinical case specified.

There is unanimity among the analysts that the word is an essential tool in the therapeutic task. It must also be considered basic for the assigning of names to human suffering, so that we can more successfully find, together with the patient, the possible solution to his uneasiness.

Key words: Psychoanalytic process, diagnosis, clinical case 